
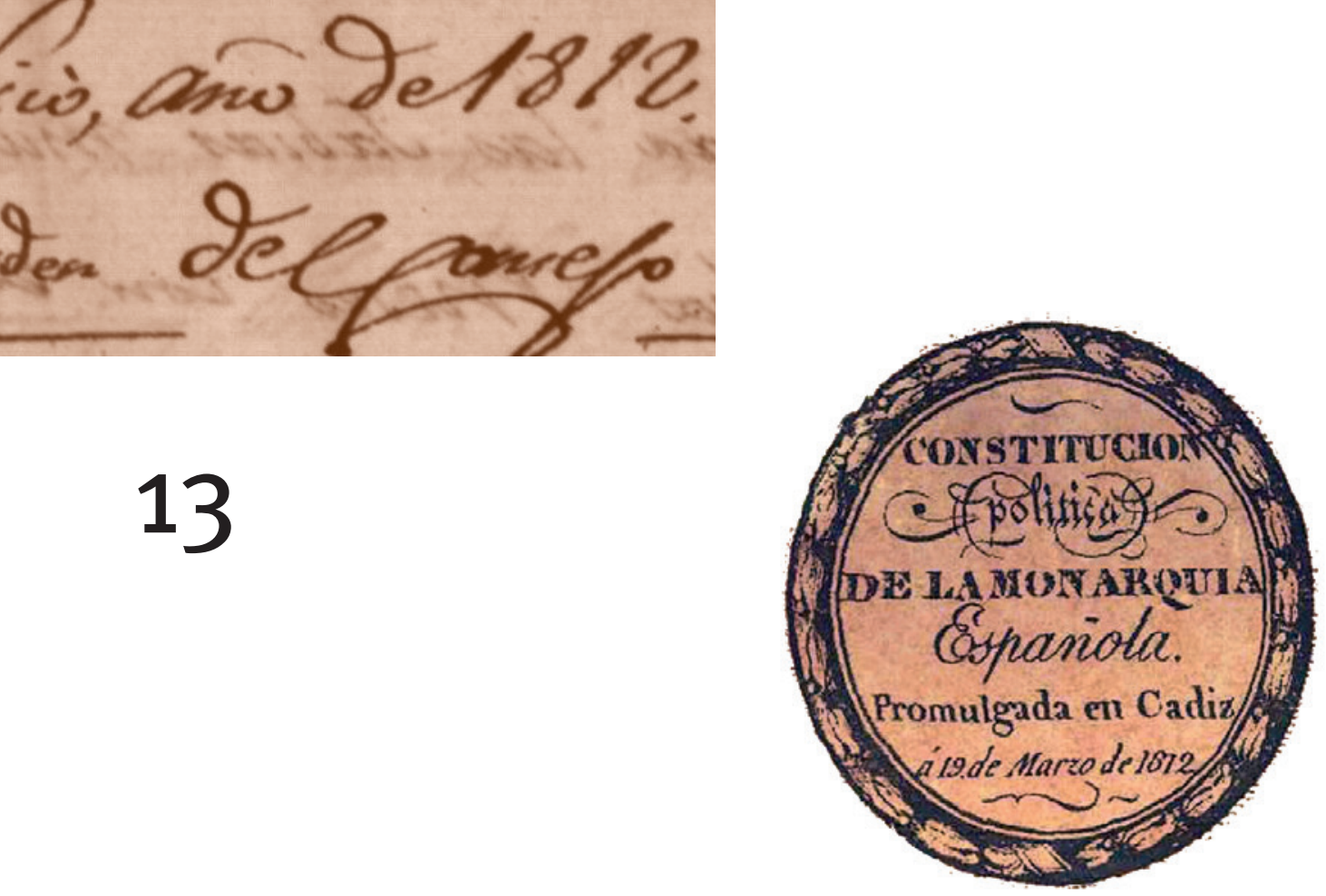

13

romulgada en Cadiz
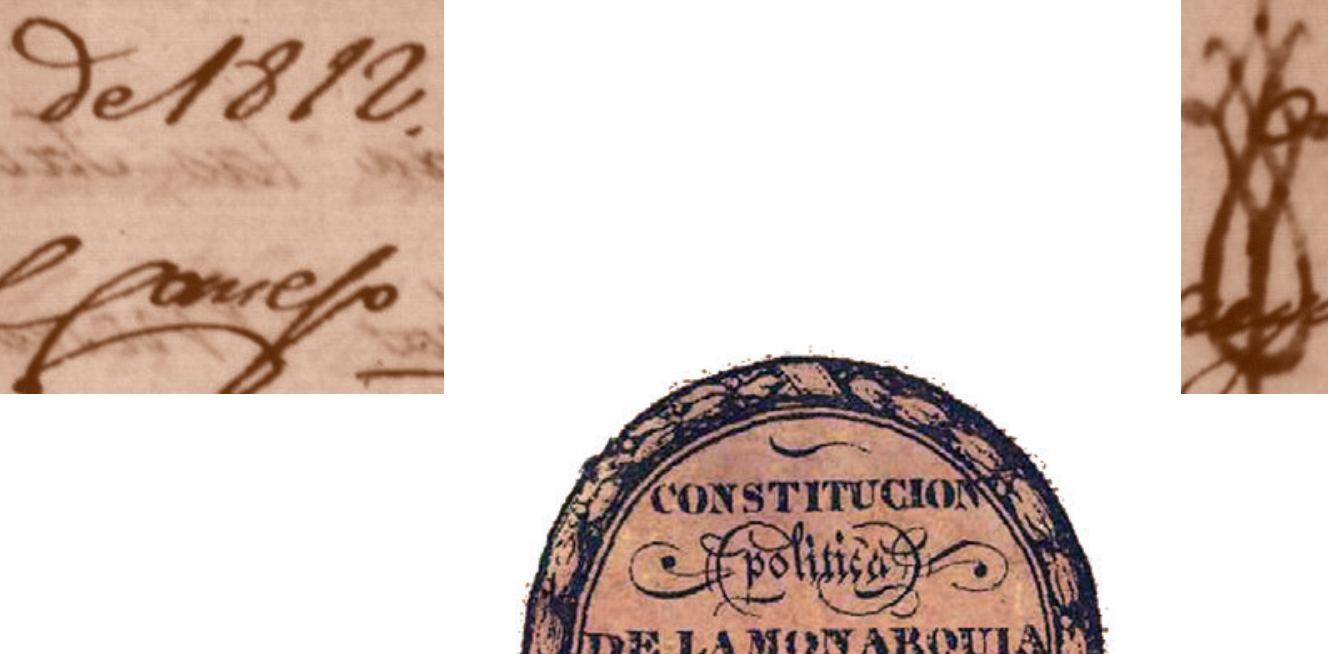



\section{Colección $\mathbf{I m u d}$ \\ n. ${ }^{\text {13 }}$}

\section{LA PROVINCIA DE LA MANCHA Y LA CONSTITUCIÓN DE 1812}





\section{Carlos Chaparro Contreras \\ e Isidro Sánchez Sánchez (eds.)}

\section{LA PROVINCIA DE LA MANCHA Y LA \\ CONSTITUCIÓN DE 1812}

Ediciones de la Universidad

de Castilla-La Mancha

Cuenca, 2021 
LA PROVINCIA de La Mancha y la Constitución de 1812 / editores, Carlos Chaparro Contreras, Isidro Sánchez Sánchez.- Cuenca : Ediciones de la Universidad de Castilla-La Mancha, 2020

341 p. ; 24 cm.- (Almud ; 13)

ISBN 978-84-9044-311-8

1. España - Constitución - 1812 2. Castilla-La Mancha - Historia I. Chaparro Contreras, Carlos, ed. lit. II. Sánchez Sánchez Isidro, ed. lit. III. Universidad de Castilla-La Mancha, ed. IV. Serie

342.4(460)"1812"

946.028

1DSE-ES-G

NHD

(C) de los textos e imágenes: sus autores.

(C) de la edición: Universidad de Castilla-La Mancha.

Edita: Ediciones de la Universidad de Castilla-La Mancha y Centro de Estudios de Castilla-La Mancha.

Colección Almud n. ${ }^{\circ} 13$.

Diseño de la colección:

C.I.D.I. (Universidad de Castilla-La Mancha).

unte Unión de Edtorlales
Universitarias Españolas nacional.

Esta editorial es miembro de la UNE, lo que garantiza la difusión y comercialización de sus publicaciones a nivel nacional e inter-

ISSN: $1988-0979$

I.S.B.N.: 978-84-9044-311-8 (Edición impresa)

I.S.B.N.: 978-84-9044-434-4 (Edición electrónica)

D.O.I.: http://doi.org/10.18239/alm_2021.13.00

D.L.: CU 248-2019

Composición: Compobell S.L.

Impresión: Gráficas Izquierdo

Hecho en España (U.E.) - Made in Spain (U.E.)

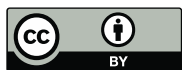

Esta obra se encuentra bajo una licencia internacional Creative Commons CC BY 4.0.

Cualquier forma de reproducción, distribución, comunicación pública o transformación de esta obra no incluida en la licencia Cretative Commons CC BY 4.0 solo puede ser realizada con la autorización expresa de los titulares, salvo excepción prevista por la ley. Puede Ud. acceder al texto completo de la licencia en este enlace: https://creativecommons.org/licenses/by/4.0/deed.es 


\section{ÍNDICE}

Presentación ..................................................................................

Gabino Marco Solera, Carmen María Montalbán Martínez y Antonio Ruiz Lucas

Las Cortes y la Constitución de Cádiz: contenidos sociales y esperanzas populares

Juan Sisinio Pérez Garzón

La Constitución de 1812

Enrique Belda Pérez-Pedrero

Guerra y revolución en La Mancha Ángel Ramón del Valle Calzado

El Partido de Alcaraz a finales del Antiguo Régimen

65 Carmen Hernández López y Francisco García González

"Napoleón emperador" y el destino del Partido de Almagro......... José Gregorio Cayuela Fernández

La Mancha, 1812: El partido judicial de Villanueva de los Infantes Lucía Crespo Jiménez

Representación y educación político-popular en las ceremonias y fiestas de proclamación y jura de la Constitución de 1812 en La Mancha

Carlos Chaparro Contreras

La crisis del Antiguo Régimen en La Mancha (1787-1808). El caso de Villanueva de los Infantes y su partido.... Carlos Javier Rubio Martínez 
Los manchegos que auparon a la "Pepa"

Enrique Jiménez Villalta

Almadén y la Constitución de Cádiz (1812-1814)

245

Julián Prior Cabanillas

El padre Agustín de Castro y la prensa periódica

273 Isidro Sánchez Sánchez 


\title{
LA CRISIS DEL ANTIGUO RÉGIMEN EN LA MANCHA (1787-1808). EL CASO DE VILLANUEVA DE LOS INFANTES Y SU PARTIDO
}

\author{
CARLOS JAVIER RUBIO MARTÍNEZ \\ Historiador y Profesor del IES Briocense (BRIHUEGa)
}

En el último tercio del siglo XVIII España asistió a un periodo de crisis y reformas que desencadenaron el colapso de las instituciones del Antiguo Régimen y el alumbramiento del sistema liberal, todo ello bajo la influencia de un contexto internacional de gran convulsión. La provincia de $\mathrm{La}$ Mancha, favorecida por algunos destellos de Ilustración por parte de aristócratas vinculados a la región, animada a modernizar su campo y condicionada por la liberalización de los productos agrícolas, se abrió hacia una reordenación de su economía, su sociedad, su población y sus instituciones.

La provincia sufrió con ímpetu los efectos de los brotes epidémicos finiseculares y la proletarización de su sociedad, generándose a partir de éstos y de las crisis hacendística y de subsistencias, conatos de motín, robos, desórdenes públicos y desacatos al orden establecido; efectos que no solo se manifestaron en el estamento más débil, sino también en los grupos privilegiados y en los que ostentaban el poder político. A continuación intentaremos detallar estos aspectos tomando como muestra el caso de Villanueva de los Infantes y su partido.

\section{LA CRISIS DEMOGRÁFICA}

Villanueva de los Infantes era a mediados del siglo XVIII una de las cuatro cabezas de gobernación de la Orden de Santiago y capital de uno de los tres partidos de la Provincia de La Mancha. En el censo de 1751 contaba con una población de 5.815 habitantes, equiparable a la de Valdepeñas (5.588 hab.) o a la de La Solana (5.988 hab.), y sólo superada con cierta diferencia por Villarrobledo, Daimiel, Ciudad Real y 
Almagro; villas que tenían una población de entre los seis y los ocho mil habitantes ${ }^{1}$. No obstante, en la segunda mitad del siglo, la villa, al igual que el Campo de Montiel, mostraron un marcado estancamiento demográfico que contrasta con la evolución provincial. En 1787 Infantes contaba con 5.732 habitantes. En esa misma fecha Valdepeñas ya había alcanzado los 7.768 habitantes, Manzanares despuntaba con 6.806, y Daimiel y Almagro superaban los 9.000².

Tradicionalmente se ha achacado este estancamiento a la reordenación de la infraestructura caminera en la provincia, pero este factor resulta insuficiente, ya que, como vemos en la tabla 1, otras comarcas que no se beneficiaron de la red de carreras de postas de Carlos III, también experimentaron un crecimiento.

\section{Tabla 1. Media de habitantes de los MUNiCiPIOS DE LA PROVINCIA DE LA MANCHA}

\begin{tabular}{|c|l|c|c|r|}
\hline $\begin{array}{c}\mathrm{N}^{\circ} \\
\text { mun. }\end{array}$ & \multicolumn{1}{|c|}{ Partidos } & 1751 & 1787 & \multicolumn{1}{c|}{ Variación } \\
\hline 18 & Alcaraz & 1.841 & 2.151 & 116,83 \\
44 & Calatrava & 2.107 & 2.524 & 119,80 \\
22 & Montiel & 1.423 & 1.421 & 99,89 \\
12 & Agregados al C. de Montiel & 1.907 & 2.136 & 112,03 \\
\hline 96 & Medias totales & 1.875 & 2.153 & 114,80 \\
\hline
\end{tabular}

Con toda probabilidad, las razones del estancamiento de Villanueva de los Infantes y del Campo de Montiel a lo largo de la segunda mitad del siglo XVIII haya que encontrarlas en las dificultades para desarrollar allí un aumento de la producción agrícola. En este sentido, la escasez de agua fue un problema para extender el regadío, y aunque se propusieron medidas, como la de abrir los Ojos de Montiel o la de trasvasar agua de las Lagunas de Ruidera al Azuer, ninguna de ellas llegó a materializarse.

La solución ante estos problemas fue la roturación de las dehesas. Medidas de carácter extensivo que no hicieron mejorar los rendimientos agrícolas. Las dehesas concejiles eran en 1575 solamente de pasto, pero posteriormente se dieron licencias de rotura, práctica que se suspendió en 1750. En 1797 los pegujaleros de la villa enviaron un recurso al Con-

1 J. López Salazar: "Evolución demográfica de La Mancha en el siglo XVIII" en Hispania, Madrid, $\mathrm{n}^{\circ} 133$ (1976), pp. 233-299.

2 J. López Salazar: “Evolución demográfica...”, p. 290. 
sejo de Castilla para convertirlas en dehesas de pasto y labor de manera perpetua. En 1800 lo consiguieron para las dehesas Vieja y Nueva, pero los poderosos de la villa, aprovechando el control de la junta de Propios, dirigieron el reparto y se incluyeron ellos mismos junto a los pegujaleros "braceros"; dejando fuera a los pegujaleros "menestrales", lo que les causó un gran descontento, más aún cuando éstos últimos habían participado económicamente en los gastos de la petición ${ }^{3}$.

Por tanto, a finales del siglo XVIII la agricultura infanteña seguía dependiendo de las condiciones climáticas, valoración que ya transmitió el propio Larruga ${ }^{4}$. Este hecho pudo hacer más vulnerable a la zona con respecto a otras de su entorno durante las variaciones climáticas finiseculares y las consecuencias epidémicas. Así, el periodo 1783-1785 fue alarmantemente lluvioso. Por ejemplo, el párroco de Socuéllamos registró en su libro de matrimonios cómo desde el 11 de septiembre de 1783 hasta primeros de junio del año siguiente se habían producido imparables precipitaciones acompañadas de fuertes vientos ${ }^{5}$. Durante estos años quedaron inutilizables los puentes que rodeaban Villanueva de los Infantes. De hecho, el Jabalón había llegado a mudar su curso en la zona de Triviño, por lo que tuvo que construirse en 1786 un nuevo puente de dos ojos y elevar la calzada mediante una plataforma de piedra hasta enlazar con el puente viejo ${ }^{6}$. En aquel año también se reconstruyó por completo el puente de La Virgen y se intervino en los puentes de Batalla, del Águila y del Camino de Cózar7.

Debido a esta situación climática, el temor por el futuro de las siembras fue constante. Un método paliativo fue traer a la población a la patrona de la villa, la Virgen de la Antigua, y realizarle rogativas o fiestas en acción de gracias, como las que se hicieron en los meses de noviembre de 1794 y de 1796; y de mayo de 1798 y $1799^{\circ}$. Además de estos temores, también fueron problemáticas las plagas de langosta, que sufrió la comarca en 1791 y 1792 y toda la provincia entre 1804 y $1808^{9}$.

3 AHPCR. Protocolos, P-768, 1800, fol. 23r-24v. 17 de marzo.

4 E. Larruga, Memorias políticas y económicas sobre los frutos, comercio, fábricas y minas de España, tomo XVII, imp. Antonio Espinosa, Madrid, 1792, p. 9.

5 P. San Andrés Galiana, Socuéllamos. Historia de Socuéllamos, datos y documentos recopilados de archivos, Socuéllamos, Gráficas Aurora, 1996, p. 122-123.

6 J. J. Espadas Pavón y P. R. Moya Maleno, “Un 'Puente Romano' sobre el río Jabalón (Villanueva de los Infantes, Ciudad Real, España): el Campo de Montiel como zona de paso desde la Antigüedad", Hispania Romana: Actas do IV Congresso de Arqueologia Peninsular, Universidad de Algarve, Faro, 2008, pp. 283-297.

7 J. Díaz Pintado, Conflicto social, marginación y mentalidades en La Mancha (siglo XVIII), Ciudad Real, BAM, 1987, pp. 289-290. El presupuesto de 21.424 rs. denota la envergadura de la obra.

8 AHMVI, Actas municipales de 1794. Caja 61.1, Sin foliar (s.f.).

9 J. Díaz Pintado, "Climatología de La Mancha durante el siglo XVIII", en Cuadernos de Historia Moderna, Madrid, nº 12 (1991), p. 146. 
Los problemas climáticos desencadenaron problemas demográficos, con altas tasas de mortalidad durante todo el periodo. Las lluvias de 1783-1785 favorecieron la aparición de enfermedades palúdicas, en las que influían las aguas estancadas o de curso lento. Una fuerte epidemia sacudió España a partir de 1783 y con gran intensidad se registró en La Mancha entre 1785 y $1787^{10}$. A partir de 1800, los niveles de mortalidad se dispararon como consecuencia de la epidemia de fiebre amarilla que se había iniciado en Cádiz en agosto de ese año. Esta epidemia saltó muy pronto a Sevilla, Triana, Jerez y otros puntos de Andalucía; de modo que a mediados de septiembre alcanzaba la carrera de Andalucía, donde llegaban a verse trajineros enfermos.

El ayuntamiento de Infantes, consciente de que la villa era zona de tránsito de andaluces con dirección a Valencia y Murcia, decretó, el 17 de septiembre de 1800, que ni los mesoneros ni los vecinos en general admitiesen a personas provenientes de Andalucía o de otros puntos donde se padeciese la peste, que tampoco comprasen ropas ni comestibles que se hubieran sacado de Andalucía desde hacía tres meses, incluido el aceite revendido en otros pueblos cercanos. Los vecinos debían dar cuenta a la justica de dichos transeúntes para que los retirasen a los campos ${ }^{11}$. Por su parte, algunos profesionales de la salud remitieron cartas al ayuntamiento ofreciendo colaboración. El médico don Francisco José de Rivas y Peralta se prestaba para ser nombrado médico de los caminantes contagiados. Además, informaba a los capitulares de que el peligro estaba en el viento ábrego, procedente de Andalucía, y en los pobres y miserables de la población, que, teniendo hasta el momento el alojamiento en las ermitas, podían entrar en contacto con los forasteros enfermos. Por ello, pedía que estos pobres se realojasen en otros lugares más seguros $^{12}$. Otro médico, el doctor don Julián de Diego, escribía otra carta al ayuntamiento, el 25 de septiembre de 1800, con otra serie de medidas:

"Una de las cosas y más eficaces medicamentos que hasta el presente la práctica nos tiene demostrado, [que] son los más eficaces para la curación y precaución de la peste, son las súplicas y deprecaciones al Todo Poderoso y las súplicas y rogativas a los santos titulares o patronos de los pueblos; y especialmente aquellos de quien repetidas veces han recibido auxilios. Y siendo en esta villa suma la confianza que tienen en la Virgen de la Antigua, por los repetidos casos que han experimentado a este Ilustre Ayuntamiento, suplico, si lo halla por conveniente, empezar a poner los medios para precaverse de la peste

10 J. López Salazar: "Evolución demográfica...”, pp. 275-277.

11 AHMVI, Actas municipales de 1800. Caja 66.4, 17, s.f.

12 AHMVI, Actas municipales de 1800. Caja 66.4, s.f. 
mandando traer a dicha imagen a la Parroquial para hacerle sus cultos y súplicas, mandando al mismo tiempo hacer luminarias al anochecer por todo el pueblo, con cantueso, romero y enebro, regar las casas con agua y vinagre, y que las gentes lleven un pañito embebido en vinagre oliéndole de cuando en cuando. [Que] bajo de rigurosas penas ningún vecino admita ningún forastero en sus casas sin que dé parte al tribunal de cómo viene y dónde para, que éste tome las precauciones necesarias para si se ha de introducir en el pueblo o no, que es cuanto por ahora le parece conducente para precaverse de este contagio" 13

Los capitulares consideraron la propuesta del doctor, y programaron la procesión y traída de la soberana imagen para la tarde del domingo 28 de septiembre; igualmente, los mismos ya habían programado días antes la necesidad de formar una junta de médicos para concretar mejor las acciones a desarrollar ${ }^{14}$. No obstante, los resultados fueron inútiles. La fiebre amarilla llegó a la población y representó entre 1801 y 1807 el 33,3 por ciento de las causas de muerte. Hubo repuntes de esta fiebre en 1805,1806 y 1809 , donde la enfermedad superó el 45 por ciento ${ }^{15}$.

\section{LA CRISIS SOCIOECONÓMICA}

La sociedad infanteña manifestó durante la segunda mitad del siglo XVIII un acusado proceso de proletarización. Como indicador, el número de jornaleros en Infantes llegó prácticamente a duplicarse en los años que intermedian 1752 y 1786 . Pasaron de 348 a 633 personas $^{16}$. Según un informe agrícola, realizado por varios capitulares del ayuntamiento en 1794, se criticó un hábito que puede explicar este proceso. Relata cómo determinados menestrales y criados de labor aspiraban a convertirse en pegujaleros o labrantines, comprando tierras de mala calidad, intentando darles un rendimiento. En esta actividad desatendían sus ocupaciones principales, alteraban el precio de los jornales, y a la larga podían quedar endeudados con el pósito, arruinados y acabar como jornaleros sin amo o en mendigos. Por ello, los capitulares pedían mayor proteccionismo a la agricultura y que ésta se limitase para aquellos que fueran capaces de sostenerla ${ }^{17}$.

13 Ídem.

14 Ídem.

15 F. J. Campos y Fernández de Sevilla, "Demografía Manchega”, en Anuario del Real Colegio de Alfonso XII, San Lorenzo del Escorial, 1 (1983).

16 Confróntense datos del Catastro de Ensenada y del censo de Floridablanca.

17 F. J. Campos Fernández de Sevilla, "Panorama de la agricultura en Villanueva de los Infantes a fines del siglo XVIII", en Cuadernos de Estudios Manchegos, Ciudad Real, no 34 (2009), pp. 377-415. 
En este fenómeno parece indudable que tuvo mucho que ver la liberalización del cereal y las posibilidades especulativas que éste presentaba. Cosecheros y comerciantes podían tomar por actividad atesorar el grano durante el año para decidir sacarlo en los meses de mayor carestía, mayo $\mathrm{y}$ junio, $\mathrm{y}$ venderlos a precios desorbitados en zonas urbanas del reino; dejando a las villas manchegas mal abastecidas y con precios muy alterados. Es muy posible que, ante esta situación, los artesanos y los criados de labor pretendieran comprar tierras y hacerse pegujaleros. Así podían hacer frente a estas manipulaciones y, por qué no, también especular. A pesar de la compra de tierras, en la práctica, los pegujaleros siguieron a merced de los grandes cosecheros, ya que éstos últimos eran quienes mejor podían controlar los precios y quienes contaban con excedentes suficientes como para financiarlos a crédito como simiente.

Si la situación se tornaba delicada, las últimas décadas del siglo la agravaron todavía más, ya que las guerras surgidas a raíz de la Revolución francesa, la crisis de la real hacienda, la expansión de la fiebre amarilla y la langosta atenazaron una dura crisis mixta: hacendística, epidémica y malthusiana; donde los recursos naturales disponibles, en valores absolutos, llegaron a ser muy inferiores a la población que pretendía consumirlos. De la carestía ficticia que provocaban los especuladores se había pasado a una carestía real.

En este sentido, para solventar la crisis hacendística se pidieron donativos, se desamortizó y se expidieron títulos de deuda pública, como los vales reales. En 1798 Carlos IV recurrió a instar a los estamentos privilegiados para que participasen en un "préstamo patriótico"18. El mismo año se dio permiso para la desamortización de bienes raíces de instituciones religiosas de naturaleza pública, como hospitales, obras pías, patronatos o cofradías. El envite a estas instituciones se debía a su

18 Lectura del Alcalde Mayor, García Varona, a los grupos privilegiados de Infantes: "Vosotros que apreciáis ser de la mas esclarecida parte del rebaño de la Santa Madre Iglesia Católica, vosotros que blasonáis por tan justos títulos ser aquella porción escogida, cuyos timbres, gentilicios, y familiares manifiestan haber sido la que recuperó y consolidó la religión cristiana y el Estado en los verdaderos y legítimos españoles... No ignoráis las estrechas urgencias del Estado en una guerra larga y continuada y que si por ella no se atendiera a vuestra seguridad y defensa los ricos dejaríais de serlo, al paso que vuestra distinguida clase vendría a reducirse a confusión, igualdad y trastorno. Os haría el mayor agravio de todos si no contemplase en vuestros corazones, sellados por medio de los infalibles principios de nuestra Santa Religión, el amor, respeto, subordinación y obligación de justicia de contribuir y devolver al César lo que es suyo... Fundadas en estas santas y sagradas máximas, bien sabéis que nuestro monarca para conservar el tabernáculo templo y muros de la gran Jerusalén ha usado del donativo a imitación de Moisés que se valió de él para la fábrica del tabernáculo de David, para la del templo y de exedras, para reedificar los muros de Jerusalén: este arbitrio de la benevolencia no dudo que excitará enteramente a vuestros ánimos y que por granjearos el título de bienhechores de la patria y de leales y fieles vasallos quedarán avergonzadas estas mis insinuaciones que por obedecer a la superioridad le ha sido forzoso a mi cortedad publicar", AMVI, Actas Municipales de 1798. Caja 66.1, s.f. 
escasa utilidad ya que en muchas de ellas se habían degradado los fines por los que se crearon. Gracias a esta desamortización se pudo llevar a cabo la venta en almoneda de las tres casas que el presbítero y teniente de la parroquia, don Diego Ventura del Prior, dejó por obra pía, a principios del siglo XVIII, para la ermita de Ntra. Sra. de los Remedios. Por último, la quiebra llevó al gobierno a solicitar en 1800 un subsidio de 300 millones de reales a repartir por el reino. Los ayuntamientos se vieron encarados a establecer arbitrios y tomar medidas extraordinarias, entre las que se contempló la venta de grano de los pósitos. En concreto, en este subsidio, Villanueva de los Infantes tenía que aportar la cantidad de 20.962 reales con $10 \mathrm{mrs}^{19}$.

De esta forma, el siglo XIX comenzaba con las arcas municipales vacías y con el precio del cereal en manos de los especuladores. La sociedad, completamente debilitada económicamente, se vio empujada a recurrir al motín. Precisamente, en 1802 los vecinos de algunos pueblos de las provincias de Toledo, La Mancha y Madrid se amotinaron ante la falta de cereal y el excesivo precio que había adquirido. Estos pueblos fueron Tembleque, Getafe, Leganés, Mora, Madridejos, Mascaraque, Villamuelas, Villanueva de Bogas, Herencia y Manzanares. Una geografía que nos muestra claramente la fuerza especulativa que generaban las demandas de Madrid y Aranjuez en las zonas manchegas.

Infantes no se escapó de esta situación, pues aquí ejercía influencia, junto a Madrid, las regiones de Valencia y Murcia. La fanega llegó, en la villa, al precio de 100 reales en los meses de mayo y junio de ese año, y parece que faltó poco para producirse una sublevación, aunque el texto no lo deja bien claro. No obstante, lo que sí sacaron en claro de aquella experiencia los especuladores fue que había que atesorar grano para esos meses grandes de 1803, por lo que ya en agosto de 1802 se experimentaba una inexplicable escasez de grano en la villa. Por ello, el alcalde mayor, García Varona, tuvo que informar al Consejo de Castilla:

"El haberme visto en el mayor compromiso de sublevación en los meses más próximos pasados de mayo y junio con motivo de la escasez de granos, excesiva saca de ellos, escandalosa alteración de precios y hambre popular que hubo no solo en este pueblo, sino en los de sus contornos, me hacen molestar la atención de vuestra excelencia para precaver las funestas consecuencias que pudiera haber en lo que falta de este año y en todo el próximo venidero hasta la recolección de sus frutos” 20

19 AHMVI, Actas municipales de 1800, Caja 66.4, s.f.

20 AHN, Consejos, legajo 6.782. exp. 18. 
El alcalde mayor reivindicaba, si no la reinstauración de la tasa, establecer una tasa regional teniendo en cuenta el recuento de lo cosechado en las distintas provincias limítrofes. Vistos los motines ocurridos, y fruto de este informe, el Consejo decretó el 11 de noviembre de 1802 una orden circular, aplicable a todo el reino, que facultaba a gobernadores y corregidores a que los especuladores vendiesen el grano a precios corrientes, y en el que recordaba la Real Cedula de 11 de noviembre de 1802, con el fin de acabar con el abuso y monopolio del grano. Debido a que el problema persistió, el 24 de mayo de 1804 el gobierno decidió reinstaurar la tasa de granos, tras cerca de cuarenta años de librecambio ${ }^{21}$.

Si el precio del cereal subió, no menos lo hizo el del pan, que produjo graves problemas en las reservas del pósito y en el trabajo de los panaderos. En esta época el ayuntamiento tenía el control del abasto de pan, el cual lo liberalizaba o estancaba según sus propios pronósticos. A pesar de liberalizarlo, solía mantener unas ordenanzas con las que fijaba un precio máximo, la obligación de los panaderos a poner su marca en el pan (con objetivo de policía), o que se hiciera, aparte del pan común de dos libras (920 gramos), pan de a libra para los más necesitados. El ayuntamiento, para garantizar el abasto, ponía las reservas de trigo del pósito a disposición de los panaderos. Era tarea de los panaderos llevar el grano al molino, amasarlo, cocerlo y venderlo o dejarlo en la calahorra ${ }^{22}$.

La pauperización social llevó al aumento del robo y los desordenes en prácticas comunes que se aplicaban contra la pobreza, como era el caso del espigueo. En junio de 1798 mucha gente que no estaba autorizada para esta práctica se echó al campo que rodeaba la villa de Infantes ocasionando numerosos desórdenes, espigando por la noche y en campos con mies, sacando crecidas porciones, provocando daños en plantíos y olivares, y actuando con desacato a la autoridad. Los capitulares se aferraron a las ordenanzas vigentes, es decir a la pérdida de lo espigado a beneficio del dueño de la tierra y a la reclusión en la cárcel. Era causa de delito encontrar porción "que verosímilmente no pueda ser espigada y sí extraída por medio ilícito" 23 .

Otro ejemplo similar fue el del absentismo laboral en criados de servidumbre, quienes, llegado el momento crítico del trabajo intensivo, se marchaban sin dar explicación ni motivos. Así lo denunciaron

21 M. García Ruipérez, Revueltas sociales, hambre y epidemia en Toledo y su provincia. La Crisis de subsistencias de 1802-1805, tesis doctoral, UCM. 1992.

22 AMVI, Actas Municipales de 1798. Caja 66.1, s.f.

23 AMVI, Actas municipales de 1798, Caja 66.1, s.f. correspondiente al 26 de junio. 
varios vecinos de Infantes ante el Gobernador en mayo de 1787. Para éstos eran muchos los que lo hacían, y especialmente las mujeres, las cuales solían "venir a parar a una vida libre y voluptuosa de que se siguen graves términos que provienen de la ociosidad". Pidieron que se tomaran medidas al modo que se hacían en otros lugares; que los acuerdos entre criados y amos se reglamentasen mediante escrituras de obligación, y que el ayuntamiento tuviera control de los criados que permanecían en cada casa ${ }^{24}$.

La delincuencia también aumentó, aumentando el número de fugitivos y bandoleros en torno a las sierras que rodean el Campo de Montiel, lo que hizo necesaria la intervención de cuerpos militares regulares y la instauración de rondines locales, como el de Infantes, con instrucción impuesta en 1800 y comandado por el Alcalde Mayor ${ }^{25}$.

La tensión social también se observó en el estamento eclesiástico, muy concretamente el clero regular, el cual, vapuleado por las ideas ilustradas, hizo chocar con el poder temporal e incluso con los seculares. De hecho, a finales de siglo, el cabildo eclesiástico, con la complicidad del ayuntamiento, promocionó el desprestigio popular de las comunidades de dominicos y trinitarios de la villa. Un ejemplo muy ilustrativo se produjo en la última década del siglo XVIII, cuando en una procesión de la Virgen de la Antigua, organizada por los padres dominicos, los miembros del cabildo no asistieron e intentaron boicotearla:

\begin{abstract}
"se añade de los buenos influjos que tuvieron los señores clérigos para intentar impedir la función de procesión que va dicha, como consultar letrados para hallar medio de abochornar ya por la tarde, y ya con querer impedir el manifiesto y función de la mañana, hasta idear hacer ellos procesión en el mismo día y tarde, a que puede añadirse que no hubo un clérigo a la puerta que recibiese la referida procesión” 26
\end{abstract}

Fray Manuel López, prior del convento de los trinitarios, quien escribió el texto que acabamos de leer, también se sentía humillado porque el cabildo ponía, en las procesiones, a tonsurados presidiendo las comunidades de frailes. Por ello es que, en 1798, cuando el ayuntamiento reclamó la participación de los regulares en la procesión en acción de gracias a la Virgen de la Antigua, programada para el 7 de mayo, los trinitarios y dominicos intentaron no asistir ${ }^{27}$. Alegaban que

24 AHMVI, Actas municipales de 1787, Caja 56.4, s.f.

25 J. Díaz Pintado, Conflicto social..., p. 125.

26 AMVI, Actas municipales de 1798, Caja 66.1, s.f.

27 Ídem. 
no estaban obligados por tratarse de una procesión extraordinaria. En su defensa, el ayuntamiento argumentó que el cabildo no había tenido nada que ver con la organización y la fecha de dicha procesión, sino que éstas habían sido dadas por el común de los vecinos, y que era precisa la asistencia de los frailes para dar solemnidad y "para evitar el bochorno al ayuntamiento y nota al público, que no conviene tenga noticia de estas ocurrencias”. Realmente, los frailes sabían de una complicidad encubierta. Los trinitarios organizaban para ese mismo siete de mayo la procesión de la Virgen del Rosario.

\section{LA CRISIS POlítica. El GOBIERNO DE LORENZANA}

La actividad y las instituciones políticas no quedaron fuera de la crisis. Los poderosos fueron acusados de ser, si no causantes, al menos responsables del hambre y la falta de grano. Se hicieron comunes los enfrentamientos con la oligarquía. El caso del posible motín de 1802 es suficiente para observarlo. Los grupos que no participaban en el poder se mantuvieron atentos en la gestión pública. En Alhambra, por ejemplo, el párroco don Juan Gámir llegó a establecer en su domicilio una especie de ayuntamiento paralelo que vigilaba las cuentas del legítimo ${ }^{28}$. En Villanueva de los Infantes y su partido tenemos algunos datos que nos ilustran la actividad política comarcal durante este periodo, la cual estuvo ejercida por su gobernador don Juan Álvarez Lorenzana.

Don Juan Álvarez Lorenzana (c. 1721-1809), era hijo de don Manuel y doña Paula Gago, oriunda la madre de Pradilla, aldea de Toreno (León). Lorenzana, como su padre, era natural de San Miguel de Laciana, aldea de Villablino (León). En su juventud ingresó en el ejército en Seseña, como carabinero real. Durante este periodo fue investigado por los sucesos del Motín de Esquilache, ya que mantenía relación epistolar con el jesuita Isidoro López ${ }^{29}$. Exculpado del proceso, se reivindicó la restauración de su honor. Su comandante, el duque de Huéscar, pidió que fuera ascendido a teniente ${ }^{30}$; y en 1768 fue nombrado caballero de Calatrava ${ }^{31}$. Se manifestó como hombre ilustrado al entrar en varias sociedades económicas de Amigos del País. En 1775 ingresó en la de Madrid, cuando ya tenía el cargo de capitán de carabi-

28 J. Díaz Pintado, Conflicto social..., p. 73.

29 A. Ferrer del Río, Historia del reinado de Carlos III en España. Madrid, Imprenta de los Señores Matute y Compagni, Cap. III. 1856.

30 Ídem.

31 AHN, Expedientillos de Ordenes Militares, $\mathrm{n}^{\circ} 12276$. 
neros reales y habilitado de brigada ${ }^{32}$. En 1781 ingresó en la Vasconga$\mathrm{da}^{33}$. Cuando fue nombrado gobernador de Infantes, en 1787, estaba entrado en años y era coronel de los reales ejércitos.

En cuanto a su vida privada, Lorenzana se casó dos veces, con doña Claudia Gómez del Casal y después con doña María Manuela Sedano y Lara. Ninguna de las dos esposas le aportaron descendencia. No obstante, sí tuvo dos hijos naturales con doña Antonia Simón Jamuda: don José y doña María Teresa ${ }^{34}$. Doña María Teresa había nacido en Madrid hacia 1780, se avecindó en Infantes y se casó el 25 de julio de 1808 con don Miguel de Arellano, un viudo que era tesorero de las rentas reales de la villa, 16 años mayor que ella ${ }^{35}$. Lorenzana no era una persona de fuertes caudales, como manifestó en su testamento. Tan solo tenía como objetos de preciado valor una escultura de niño Jesús en una urna de cristal, dos bandejas y dos candeleros de plata, y un juego completo de barbería, también de plata. El entierro lo dispuso que se hiciera "con la moderación que exige la falta de medios con que me encuentro, y de cuya satisfacción entiendo no poder salir en el resto de su vida" ${ }^{36}$. Lorenzana murió de tabardillo (fiebre amarilla) el 15 de marzo de 1809 y se le enterró en el cementerio de San Juan en el tramo de eclesiásticos ${ }^{37}$.

Lorenzana entró en 1787 en el gobierno de Villanueva de los Infantes con la vitalidad regeneracionista propia de un miembro de los dos clubes patrióticos más importantes del país. Así lo mostró en la visita que hizo a los pueblos del partido en el otoño de ese año. Por ejemplo, en Villahermosa el 8 de octubre hizo publicar un edicto a favor del civismo y del orden público. Con él además pretendía mejorar el aspecto urbano mandando que los vecinos mantuvieran limpios y desembarazados de carros sus tramos de calle o que eliminasen los arbollones que daban a vías públicas. Al ayuntamiento le mandó alejar los muladares de la población, mejorar la compostura de las entradas del pueblo, así como empedrar la plaza pública y calles aledañas ${ }^{38}$. El 13 de octubre se encontraba en Chiclana de Segura. Debido a estar emplazada la villa en una escarpada ladera que sufría abundantes

32 A. Manuel del Moral Roncal, "Los socios militares de la Real Sociedad Económica Matritense de Amigos del País (1775-1815)”, en Militaria, Madrid, vol. 6 (1994), p. 112.

33 Extractos de las juntas generales celebradas por la Sociedad Bascongada de Amigos del Pais en la ciudad de vitoria por agosto de 1789. Vitoria, Baltasar de Manteli, impresor de la Real Sociedad, 1789 , p. 5 del anexo.

34 AHPCR, Protocolos, P-632, 19 de octubre de 1807.

35 APVI, Libros de desposorios, Libro 8, fol. $167 \mathrm{v}$.

36 AHPCR, Protocolos, P-632 19 de octubre de 1807.

37 APVI, Libros de defunciones, libro 4, fol. 319 r.

38 AHMVH, Edicto sobre buen comportamiento y urbanidad. Ver en Villahermosa historia $y$ Cultura. http://www.villahermosacr.es/transcripciones.htm (15-07-2012). 
desprendimientos, animó a los vecinos en mudar la villa a la cercana Loma de Manuel de José, próxima al camino de Andalucía. Se meditó el proceso y se pensó que las cargas y los censos que soportaban los edificios de la población vieja se sostendrían plantando olivares y viñas en los solares. El pueblo, reunido en asamblea le apoyó, y solo esperó la misericordia real para que éste remitiese los diezmos, contribuciones y demás arbitrios de la villa para la construcción de los edificios públicos, cosa que, según parece, no se cumplió ${ }^{39}$.

En Villanueva de los Infantes también se notó su presencia. En ese mismo año movilizó a la población para controlar la pobreza. Mandó realizar un padrón de pobres de solemnidad y constituir una Junta de Caridad que centralizase las limosnas que cada vecino daba en la puerta de su casa regularmente a lo largo del año. Dicha junta se encargaría de gestionarlas y destinarlas al mantenimiento de dicho hospital, a la manutención de los pobres y a la compra de cuatro camas. Después de haber visitado el gobernador el Hospital de los Remedios, en compañía del maestro alarife Juan Pinar, y vistas las estrechuras, se planteó la conveniencia de hacer una Casa de Caridad a las afueras del pueblo.

"no solo para curar los pobres enfermos de esa villa y su partido, sino es también para recibir y criar los niños expósitos y recoger los mendigos, huérfanos e incluirlos con el fin de proporcionarles ocupación correspondiente con que puedan ayudar a su manutención" 40

Con apartar a los pobres del centro del pueblo también se buscaban beneficios sanitarios. Mucha gente se prestó a colaborar. Lorenzana ofrecía como limosna 1.200 rs, don Juan Antonio Montiel, alcalde mayor, 300 rs; el señor Vicario 500 rs; don Tomás Valdés, don Ignacio Ortega Buenache y don Jerónimo Buenache, 2.400 rs cada uno. El rey ofreció 16.000 reales, si bien exigía que se le especificase el proyecto y se le enviasen los estatutos de dicha Junta de Caridad. No hay indicios de que el proyecto saliese adelante ${ }^{41}$.

Muy pocos de los proyectos de Lorenzana salieron adelante. No hay datos de que Lorenzana hubiera ejercido de gobernador con anterioridad a su llegada a Infantes, por lo que ante los capitulares tuvo que dar una imagen de hombre inexperto que pretendía reformarlo todo sin conocer en profundidad las costumbres y la realidad social y económica de la zona a la que había llegado. Todo esto le llevó a

39 C. Zamora Moreno, Historia de Chiclana de Segura: el pueblo, las cuevas, los asentamientos, los cortijos, Chiclana de Segura, Autor, 2003, pp. 209-221.

40 AHMVI, Actas municipales de 1787. Caja 56.4, s.f.

41 Ídem. 
una relación con las oligarquías locales tan accidentada que llegó a granjearse enemistades irreconciliables. Ante esta situación, el resto de proyectos ilustrados de Lorenzana, viables o inviables, fueron intencionadamente abortados por sus contrarios.

En este sentido, en 1791, el síndico personero de la villa había llegado a tal crispación con Lorenzana que le abrió un pleito de capitulación con ánimo de deponerle ${ }^{42}$. Éste era don Jerónimo José Fernandez Buenache y Patiño (1724-1805), heredero de la tercera casa de los Buenache en Infantes. El investigador Juan Antonio Gómez, en un reciente y extenso estudio, sitúa el origen de las desavenencias en las cuentas del pósito. Parece ser que Lorenzana era partidario de ampliar las sacas y Buenache estaba muy preocupado por la conservación de los caudales, por lo que Buenache denunció que éste llevaba una gestión temeraria y ruinosa de los fondos públicos. Lorenzana, en cambio, se amparó en las pretensiones especulativas y despóticas de la oligarquía local que subyacían en dicha denuncia. En el pleito también fue incluido el alcalde mayor, don Juan Antonio Montiel y Bullón. En marzo de 1794, tras declarar los pleiteantes y varios testigos en el Consejo de Órdenes, el tribunal tomó a bien conceder al gobernador un permiso para regresar a su jurisdicción ${ }^{43}$. No obstante, este regreso fue aprovechado por los partidarios del gobernador para generar un tumultuoso recibimiento, que tuvo lugar la fría y encapotada tarde del 12 de abril de 1794, sábado de Ramos:

\begin{abstract}
“se verificó a las tres de la tarde... acompañado de multitud de gentes de ínfima clase, con algunos otros de otra condición que salieron en cuadrillas a recibirle fuera del pueblo a pie y a caballo haciendo salvas con tiros de arcabuces, truenos y cohetes, con extraordinarias aclamaciones en su favor, mezclados con improperios y desprecios de la familia del capitulante" ${ }^{4}$
\end{abstract}

Una parte de la comitiva, a caballo, le esperó a las afueras, en el olivar de Cercado Marín, y el grueso del común en la plazuela de San Sebastián. Después todos le acompañaron hasta la Plaza Mayor, donde se gritaron vivas y se lanzaron boinas y monteras. No era extraño que se hicieran calurosos recibimientos a la autoridad principal del lugar, como vemos en el recibimiento que le hizo Valdepeñas al Marqués de Santa

\footnotetext{
42 AHPCR, Protocolos, P-726, 31 de enero de 1805.

43 AHMVI, Actas municipales de 1794, Caja 61.1, s.f.

44 Ídem.
} 
Cruz en $17744^{45}$; pero en el caso del realizado a Lorenzana existía en él un claro carácter faccioso, tanto por las palabras que se vertieron contra los Buenache como por el visible absentismo que hicieron muchos de los capitulares del ayuntamiento. Los mozos ahondaron más la parcialidad al cantar coplas, hasta entrar bien la noche, que pasaron de la mera comparación denigratoria: "más puede Lorenzana con sus galones que los Buenache con sus doblones"; al toque inmoral: "La Virgen de la Antigua ya tiene esposo: don Juan de Lorenzana, gordo y hermoso" ${ }^{46}$. Los afectados y sus allegados no dudaron desde el primer momento de que aquel recibimiento tumultuoso no había sido espontáneo y que buscaba la intimidación. No en vano, poco después de llegar Lorenzana a la villa éste prometió públicamente vengarse del capitulante y de los testigos. En consecuencia don Jerónimo Buenache presentó dos memoriales ante el Consejo, uno explicando de los inconvenientes del permiso del que gozaba el gobernador, y otro demostrando dichos inconvenientes con el ilustrativo ejemplo del tumulto. Con ambos memoriales el capitulante pedía que Lorenzana permaneciera en Madrid durante el tiempo que durase el pleito.

Junto a estos memoriales se sumaron además otros dos recursos, uno redactado por los escribanos Alfonso Miguel Almarza, Diego Enrique y Eugenio Gallego, y el arriero Tomás López; y otro recurso por los regidores don José María García Valladolid, don Diego Tomás Ballesteros, don Isidro María Fernandez Buenache y Treviño, don Juan Antonio de Cañas y don Mateo Silvestre. En el primero los firmantes se quejaban de las venganzas vertidas hacia sus personas por haber declarado como testigos; en el segundo los regidores se solidarizaban con el capitulante quejándose de la prepotencia que había mostrado el gobernador en el sorteo de las quintas, que lo había hecho sin contar con el ayuntamiento y antes de mandarlo la corona. El 21 de octubre de 1794 el Consejo daba una resolución. Lorenzana debía permanecer en su jurisdicción, pero que

"se abstenga del conocimiento de las causas que hubiere formado contra los que fuesen testigos en el referido pleito capitulación y las pase in continenti a vuestra merced [al alcalde mayor] para que las continúe obrando con firme a derecho... Con prevención a dicho

45 J. Viera y Clavijo, Viaje a la Mancha en 1774, Almagro, IBN Clavero Fernández de Córdoba, 1995, pp. 25-28.

46 Para saber más detalles sobre este interesante tumulto: J. A. Gómez Gómez, "Auto de capitulación entre el gobernador del Campo de Montiel, Juan Álvarez de Lorenzana, y los nobles y poderosos de Villanueva de los Infantes en 1791", en Revista de Estudios del Campo de Montiel, Villanueva de los Infantes, $n^{\circ} 2$ (2011), pp. 143-171. 
gobernador de que en los ayuntamientos y juntas a que concurra trate a todos los individuos que la compongan con el honor y circunspección y urbanidad que corresponde sin manifestarles resentimiento alguno, tanto en las obras como en las palabras, porque de lo contrario se acordarán otras providencias para contenerlo" ${ }^{47}$.

Efectivamente, el Consejo de Ordenes reaccionó y se buscaron culpables del tumulto, que fueron castigados, pero Lorenzana mantuvo su plaza en Villanueva de los Infantes. Don Jerónimo parece que se quedó en Madrid, viviendo en una de las dos casas que allí tenía, una en la calle del Gato y otra en la de la Cruz ${ }^{48}$; esperando que terminase el pleito. No obstante, su espera superó a su vida, por lo que en 1805 tomaba poder su esposa para continuar la capitulación ${ }^{49}$.

Relegado de sus funciones el alcalde mayor, don Juan Antonio Montiel y Bullón, éste fue sustituido por don José de Tapia y Cueto, quien estaba casado con María Antigua Fernández Buenache, hermana de don Isidro María. Los nombramientos de estos alcaldes mayores fueron realizados por el Consejo de Órdenes y la Corona, pero está claro que en ellos tuvo mano el capitulante, por lo que la facción contraria a Lorenzana encontró en estos alcaldes mayores una fuerza con la que mantener la rivalidad. Don José de Tapia murió el 2 de septiembre de 179750, antes de terminar su cargo de seis años, por lo que el 21 de julio de 1798 llegó a la villa don Pedro Pascual García Varona para cubrir su puesto ${ }^{51}$. Lorenzana encontró en Varona una fuente de constantes desavenencias. De hecho, ambos jueces llegaron al punto de reñir, en 1800, por el palco presidencial en las corridas de toros, las cuales se celebraban en la Plaza Mayor. En vista de García Varona, ambos cargos se debían equiparar al de los dos alcaldes ordinarios de cualquier villa y, por tanto, debían compartir el palco. Sin embargo, el Consejo le dio la razón a Lorenzana, especificando que la presidencia en funciones públicas correspondía al gobernador ${ }^{52}$.

Tenemos un par de sucesos más que ilustran las relaciones hostiles entre Varona y Lorenzana. Uno de ellos se produjo durante la elección de oficios municipales del ayuntamiento de Alcubillas, en $1800^{53}$. Ambos jueces fueron a la cercana villa para dar validez al sorteo. Una vez realizado, Narciso González y Lorenzo Antonio Estévanez, vecinos de aque-

47 AHMVI, Actas municipales de 1794, Caja 61.1. s.f..

48 AHPCR, Protocolos, P-772B, 27 diciembre 1816.

49 AHPCR, Protocolos, P-726, 31 de enero de 1805.

50 APVI, Libros de defunciones, libro 3. fol. 244v.

51 AHMVI, Actas municipales de 1798, caja 66.1. s.f.

52 J. Díaz Pintado, Conflicto social..., p. 187.

53 AHPCR, Protocolos, P-768, 7 de diciembre de 1800; y protocolo de 1801, fol. 84. 
lla villa, irrumpieron el acto y pidieron que el sorteo fuera anulado y se repitiese. El alcalde mayor apoyó a los denunciantes, pero Lorenzana defendió la elección. Los denunciantes fueron a seguir el proceso en Granada, mientras los desinsaculados fueron al Consejo de Órdenes. Ambos tribunales le dieron la razón a Lorenzana, motivo que el gobernador aprovechó para presentarse en Alcubillas con soldados de a pie y de a caballo, y despojar de su cargo, "con vejación y bochorno", al alcalde en funciones, José de Campos, quien no quiso "ocasionar en el pueblo alborotos ni asonadas" por lealtad a un superior.

Otro suceso ocurrió el 6 de abril de 1803, Miércoles Santo. Aquel día Lorenzana y Varona se enzarzaron aprovechando la llegada de un arriero de Viso del Marqués, Cristóbal Baltrarazaga, que pretendía vender sardinas para esos días de abstinencia ${ }^{54}$. El arriero presumió ignorar el funcionamiento político de la villa. Gracias a ello pudo vender, con el beneplácito de García Varona, su carga al por menor. Sin embargo, parece que el gobernador tenía estancada la venta de sardinas en aquel momento, por lo que, tras ser avisado el arriero por hombres del gobernador de que no vendiese a libras y tras reincidir en su venta, fue encerrado en la cárcel. Enterados, los hombres de Varona le sacaron de la cárcel y le permitieron que continuase con la venta. En esta situación, volviendo el arriero a la casa del peso y siendo la una del mediodía, un vecino de la villa apodado Barrabás, que estaba escondido en una esquina de la Plaza, comenzó a llamar con la mano a Lorenzana, que en esos momentos estaba asomado al balcón "y con voz baja, al tiempo que hacía la seña, le decía: venga vuestra merced, que está vendiendo por libras". Y, así, se presentó el propio gobernador en la casa del peso, encerró las sardinas en ella, se llevó la llave y metió al arriero en la cárcel, donde permaneció hasta la una de la tarde del Viernes Santo.

Las malas relaciones de Lorenzana con los pueblos comarcanos y los deseos de venganza de Varona cristalizaron cuando éste dejó la alcaldía mayor de Villanueva de los Infantes en 1804 tras cumplir el periodo reglamentario de seis años. En ese mismo año las villas de Fuenllana, Montiel, Villahermosa y Cañamares constituyeron en Villahermosa una alcaldía mayor con la que consiguieron librarse de la jurisdicción de Lorenzana. La vara de alcalde la cogía aquel mismo año Varona, que ejercería el cargo con una dotación de 11.000 reales anuales ${ }^{55}$. Las disputas habían llegado a crear un nuevo partido dentro del Campo de Montiel.

54 AHPCR, Protocolos, P-781B, 1803, fol. 75-78v.

55 J. de A. Gijón Granados, La casa de Borbón y las Órdenes Militares durante el siglo XVIII (1700-1809), Tesis doctoral UCM, 2009, p. 144. 
Como denunciaban en 1806 los capitulares de Infantes, el pueblo se había convertido en "teatro lastimoso de la desunión, choque de vecinos, rencor, odio, parcialidades, bandos, semillero de pleitos, destrucción de caudales y las demás consecuencias" ${ }^{56}$. Queda por perfilar quiénes estaban en cada bando y qué elementos les unían o les separaban. En el lado contra Lorenzana, junto a don Jerónimo José Fernández Buenache, se encontraban los regidores perpetuos don José María García Valladolid, don Diego Tomás Ballesteros y don Isidro María Buenache, además del procurador don Juan Antonio de Cañas. Estos también llegaron a querellarse en Granada por los resultados en la elección de oficios de 1803, que otorgaron de síndico personero a don Miguel de Ortega, médico de la villa, y de diputado del común a Tomás Román García. Los motivos que alegaron eran, para el primer caso, que "no había necesidad de tal empleo en esta villa, por no estar enajenado de la Real Corona... ni servirse ésta por ningún individuo de los del consistorio con arreglo a lo que prescribe el real auto acordado e instrucción que tienen sobre el modo de ejecutar la elección de ciertos oficios"; y en el segundo porque Tomás Román debía unas cantidades al pósito municipal ${ }^{57}$. Igualmente, en 1806 don Isidro María entabló pleito en Granada por la protección que ofreció Lorenzana a don Antonio José Cabañero, abogado de los reales consejos de la villa y diputado del común, por la incompatibilidad de tener, a la vez, parte en el abasto de carnes ${ }^{58}$.

En cuanto al bando de Lorenzana, sus albaceas testamentarios pueden mostrarnos quiénes formaban parte de su círculo más cercano. Sus albaceas fueron su mujer doña María Manuela, su cuñado don Joaquín, el presbítero don Vicente García, don Tomás Valdés y Morales, don Francisco Corrales y, curiosamente, el Licenciado don José García Valladolid, quien parece ser llegó a cambiar de bando. De hecho, este abogado de los reales consejos era regidor desde 1787 por tenencia de la vara de su cuñado, don Juan Bautista Ibáñez ${ }^{59}$, y en 1803 don Isidro Buenache le confió la suya de alguacil mayor de millones, durante el tiempo que se ausentó de la villa ${ }^{60}$. Algo tuvo que pasar entre ambos en 1806, ya que al regresar Buenache, Valladolid decidió abandonar el ayuntamiento. Dejó la regiduría, según él, no por malicia, sino por "perder su salud por efectos del sumo trabajo en el desempeño de su regiduría, de su profesión de abogado y otras comisiones y encargos que le cercan, hallándose expuesto a perder su vida con notable detrimento de su dilatada familia" 61 .

56 J. Díaz Pintado, Conflicto social..., p. 64.

57 AHPCR, Protocolos, P-781B, 1803, fol. 52-53v.

58 AHPCR, Protocolos, P-726, 1806, 28 febrero.

59 AHPCR, Protocolos, P-726, 1806, 8 julio.

60 AHPCR, Protocolos, P-781B, 1803, fol. 81-82r.

61 AHPCR, Protocolos, P-726, 1806, 8 julio. 
Don Tomás Valdés en 1804 sufrió los escarnios de un vecino fuenllanero, José de Dueñas; población que en ese año fue incluida en la alcaldía mayor de Villahermosa, a cuyo frente estaba García Varona ${ }^{62}$. En este grupo también había que incluir a los Melgarejo, donde estaría don José Melgarejo de los Cameros, que fue teniente de gobernador durante el mandato de Lorenzana, reemplazando a don Diego Antonio Ballesteros, que lo había ejercido durante el gobierno del marqués de Valdecañas y Torremayor (1777-1787) ${ }^{63}$.

\section{Siglas UTILIZADAS}

AHMVH: Archivo Histórico Municipal de Villahermosa AHMVI Archivo Histórico Municipal de Villanueva de los Infantes AHN: Archivo Histórico Nacional AHPCR: Archivo Histórico Provincial de Ciudad Real APVI: Archivo Parroquial de Villanueva de los Infantes 